\title{
A SIMPLE FUZZY LOGIC SPEED CONTROLLER FOR A DC MOTOR FED BY SEPIC CONVERTER
}

\author{
Fahmy M. El-Khouly \\ Department of Electrical Engineering, \\ Faculty of Engineering., Minoufiya University. Egypt. \\ E-mail: Fahelkhouly@yahoo.co.uk
}

\begin{abstract}
This paper presents a closed loop speed control of a separately excited DC motor. A cascade combination of a diode bridge rectifier and single-ended primary inductor converter (SEPIC) is used to feed the DC motor from an AC supply. This circuit combination offers both step-up and step-down characteristics of the motor terminal voltage as well as an approximately sinusoidal supply current with an improved power factor. A fuzzy logic speed controller is used to overcome any system nonlinearity and parameter changes. Also. a wide range of both speed and load changes with satisfactory response is obtained. Two fuzzy membership functions are used reflecting few and simple control rules. Moreover, a genetic algorithm (GA) is used to optimally tune the fuzzy controller parameters. Simulation results of the system are obtained by solving the differential equations in different modes of operation. The system is laboratory implemented and the controller is investigated using a digital signal processing board (DSP1104). The experimental and simulation results are verified and a correlation between both has been found. The results confirm the relevance of the proposed configuration ar: a useful rectifier that achieves sinusoidal supply current, high power factor and motor speed regulator.
\end{abstract}

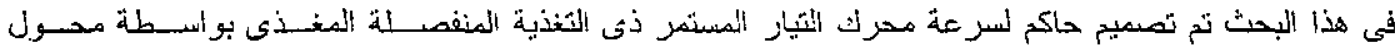

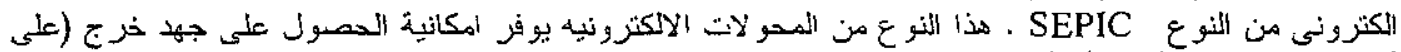

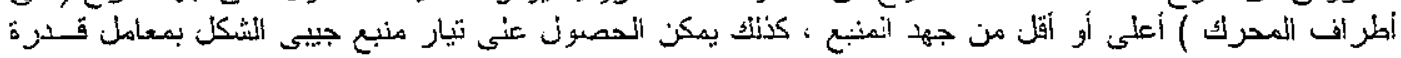
قزيب جدا من التوحدة.

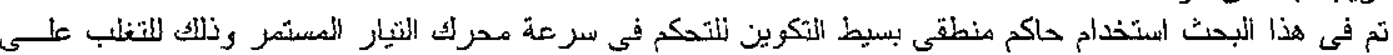

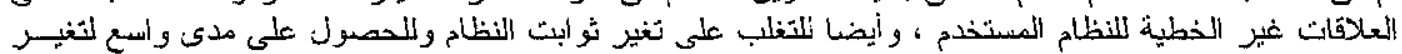

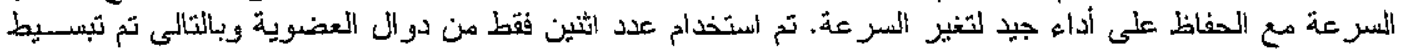

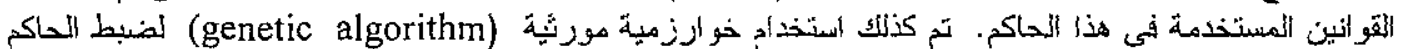

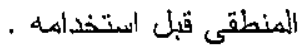

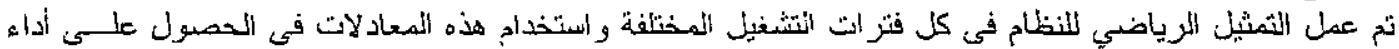

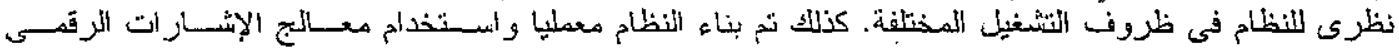

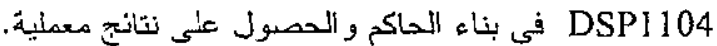

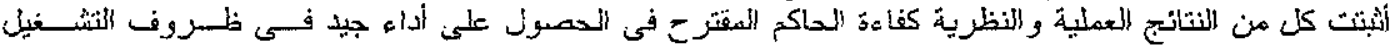

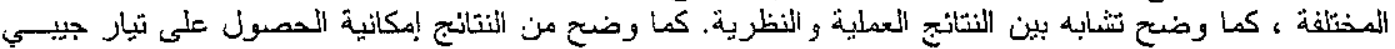

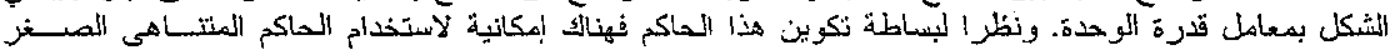
أنى microcontroller

Keywords: SEPIC converter, DC motor, Speed control, Fuzzy logic control.

\section{1-INTRODUC'TION}

Variable speed DC motor drives are utilized in multitude of applications in steel, paper processing. and mining industries. In such power electronic drives, parameter changes are caused by winding temperature variations, converter switching effects and saturation. Also, significant parameter variations come from load side, for example, in machine tool drives or robotics, the moment of inertia represents a variable parameter dependent on the tool or pay-load. Some research efforts [1-4] have been expended in control application of power electronic equipment and electrical drives. The restriction of such works is the need to dynamic simulation of the system. 
Fuzzy logic controllers and neural networks controllers have been used with such systems [5-6]. Interest in these control approaches has intensified due to their potential in circumventing parameter variation effect under dynamic conditions.

In this paper a speed control of a separately excited DC motor fed by single-phase, single-way rectifier is presented. The strategy of $\mathrm{AC}$ to $\mathrm{DC}$ converter is based on the cascade combination of diode bridge rectifier and SEPIC converter[7-8]. Step-up and stepdown characteristics of the output voltage are obtained. The supply current appears to be approximately sinusoidal with a relatively high power factor. A simple fuzzy logic speed controller is applied and a GA [9-10] is used to optimize the fuzzy controller parameters. The modeling and simulation - of this system is described in different modes of operation. Also, a laboratory implementation of the proposed system is investigated. The simulation and experimental results predict a high motor speed performance over wide range of reference speed and load changes.

\section{2- SYSTEM DESCRIPTION}

The schematic diagram of the proposed system is shown in Fig. 1. The system consists of a cascade combination of a diode bridge rectifier and SEPIC converter supplied from an AC supply. The SEPIC output is connected to a separately excited DC motor loaded by DC generator. The motor speed is fed back through the DSP1104 analog to digital converter and compared with the reference speed. FLC is used to control the motor speed and the controller output is to control the ON period of the MOSFET in the SEPIC converter and, hence, the motor applied voltage can be controlled. All parts inside the dashed line are implemented using the DSP1104 board.

The capacitor $C_{1}$ acts as a transfer element. The inductance $L_{2}$ and capacitance $C_{2}$ are used as a filter to obtain $D C$ voltage with minimum ripples. The switching frequency and the value of $\mathrm{C}_{1}$ are determined by the value of $L_{1}$. The resonance frequency $f_{r}=1 /\left(2 \pi \sqrt{ } L_{1} C_{l}\right)$, and should be sufficiently lower than the switching frequency to prevent any resonance phenomenon in the $\mathrm{AC}$ circuit. The system parameters are given in the Appendix.

\section{3- SYSTEM MODELLING}

To simulate the detailed operation, the voltage and current equations have to be established for each operating mode.

\section{1 -Mode 1:}

In this mode the MOSFET is ON and the current $i_{1}$ will flow in the loop vs- $L_{1}-r_{1}$. The capacitor $C_{1}$ will discharge and diode D is OFF, as shown in Fig. 2-a. The equations which describe this mode are given as follows:

$$
\frac{d i_{3}}{d t}=\frac{v-r_{1} i_{1}}{L_{1}}
$$

where $\mathrm{v}=\mathrm{V}_{\mathrm{m}}|\sin \omega t|$

$\frac{d v_{1}}{d t}=\frac{-i_{2}}{C_{1}}$

where $i_{1}$ and $i_{2}$ are the currents of coils 1 and 2 , respectively.

$$
\frac{d_{m}}{d t}=\frac{v_{m}-r_{m} i_{m}-k_{m} w_{m}}{L_{m}}
$$

where $v_{r}, i_{m}, w_{m}$ are motor voltage, current and speed respectively. $R_{m}$ and $L_{m}$ are motor armature resistance and inductance, respectively. $k_{m}$ is the motor back emf constant.

$$
\frac{d v_{m}}{d t}=\frac{-i_{m}}{C_{2}}
$$

where $C_{z}$ is the capacitance of the output filter.

$$
\frac{d i_{2}}{d t}=\frac{v_{11}-r_{2} i_{2}}{L_{2}}
$$

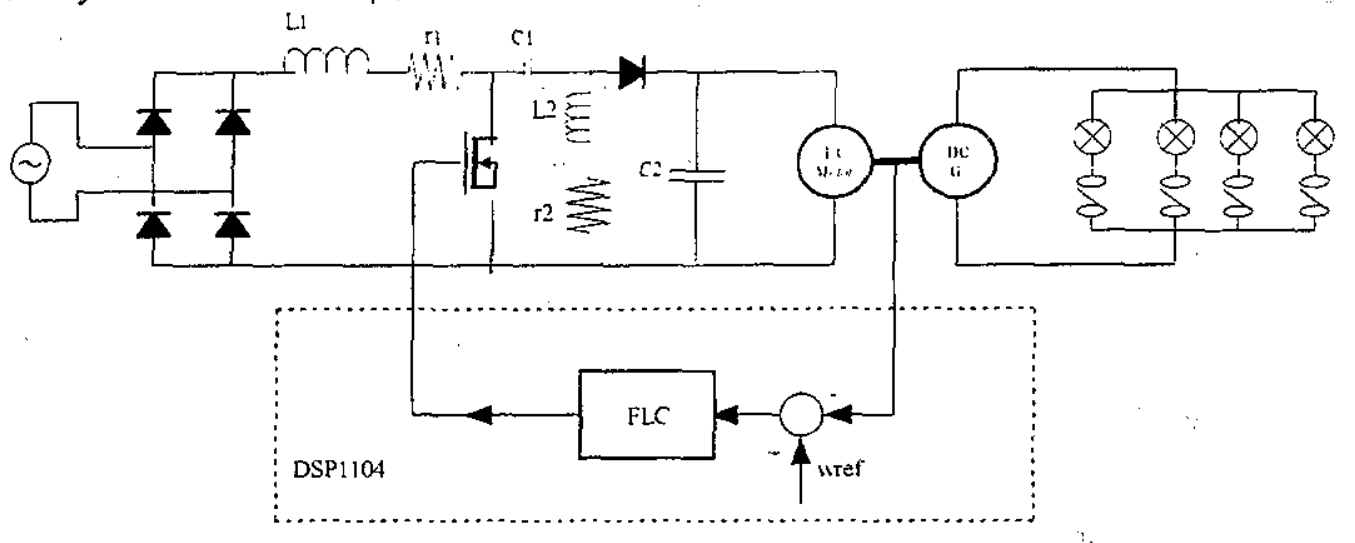

Fig. 1 Schematic Diagram of the Proposed System 
Fahmy M. El-Khouly, "A Simple Fuzzy Logic Speed Controller for a DC Motor Fed by SEPIC Converter"

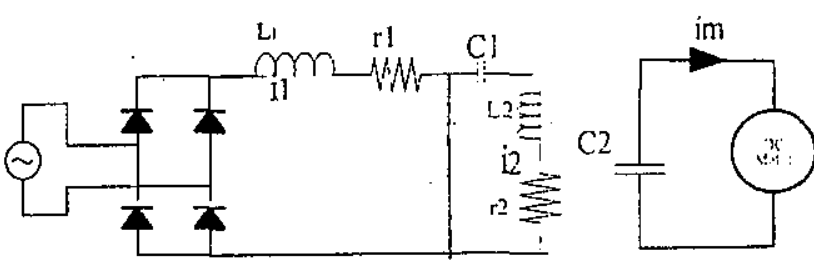

(2-a)

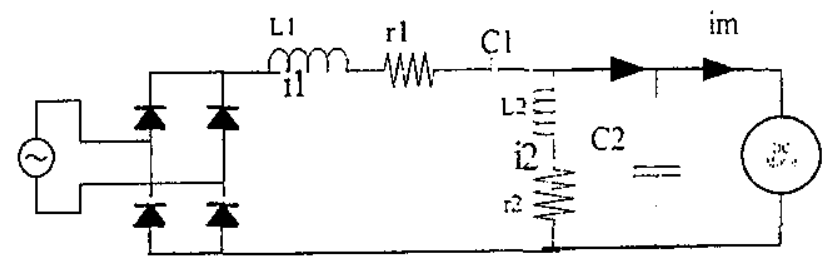

(2-b)

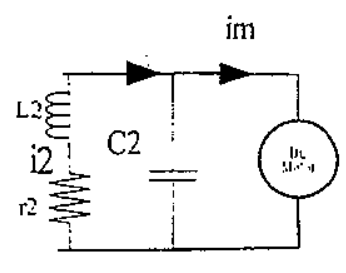

$(2-c)$

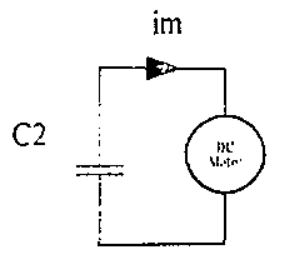

$(2-d)$

Fig. 2 System Modes of Operation

\section{2 - Mode 2:}

In this mode the MOSFET is OFF and diode $\mathrm{D}$ is $\mathrm{ON}$, as shown in Fig. 2-b. The current $i_{1}$ is greater than zero (positive). The corresponding differential eq!ations which describe this mode are given as follows:

$\frac{d i_{1}}{d t}=\frac{v-r_{1} i_{1}-v_{c 1}-v_{m}}{L_{i}}$

$\frac{d v_{c 1}}{d t}=\frac{i_{1}}{C_{1}}$

$\frac{d i_{m}}{d t}=\frac{v_{m}-r_{m} i_{m}-k_{m} w_{m}}{L_{m}}$

$\frac{d v_{m}}{d t}=\frac{i_{2}-i_{m}}{C_{2}}$

$\frac{d i_{2}}{d t}=\frac{-r_{2} i_{2}-v_{m}}{L_{2}}$

\section{3 -Mode 3:}

In this mode the MOSFET is OFF, diode $\mathrm{D}$ is ON and the current $i_{1}$ is equal to zero as shown in Fig. 2 c. The corresponding differential equations which describe this mode are given as follows:

$$
\begin{aligned}
& \frac{d i_{m}}{d t}=\frac{v_{m}-r_{m} i_{m}-k_{m} w_{m}}{L_{m}} \\
& \frac{d v_{m}}{d t}=\frac{i_{2}-i_{m}}{C_{2}} \\
& \frac{d i_{2}}{d t}=\frac{-r_{2} i_{2}-v_{m}}{L_{2}}
\end{aligned}
$$

\section{4- Mode 4:}

In this mode the MOSFET is OFF, diode D is OFF and both currents $i_{1}$ and $i_{2}$ are equal to zero as shown in Fig. 2-d. The corresponding differential equations which describe this mode are given as follows:

$$
\begin{aligned}
& \frac{d i_{m}}{d t}=\frac{v_{m}-r_{m} i_{m}-k_{m} w_{m}}{L_{m}} \\
& \frac{d v_{m}}{d t}=\frac{-i_{m}}{C_{2}}
\end{aligned}
$$

Beside the above electrical equations which describe the system in the four different modes of operation. there is the motor mechanical motion equation, which is given as:

$\frac{d w_{m}}{d i}=\frac{k_{m} i_{m}-B w_{m}-T_{1}}{J}$

\section{4- PROPOSED FUZZY LOGIC SPEED CONTROLLER}

Fuzzy logic is the logic underlying modes of reasoning which are approximate rather than exact. Thus it is closer to human reasoning and real world than formal logic. The control objective is to generate a supplementary control signal in order to enhance the motor speed following the reference speed under any disturbances with small settling time, minimum overshoot and no steady state error. At every sampling time, the motor speed deviation and scaled acceleration are denoted as $\left[\mathrm{e}_{\mathrm{w}}(\mathrm{k}), \mathrm{A}^{*} \dot{\mathrm{e}}_{\mathrm{w}}(\mathrm{k})\right]$, where $A$ is a predefined scaling factor. This condition represents a certain point, $X$, in the acceleration $\left[e_{w}(k), A^{*} \dot{e}_{w}(k)\right]$ phase plane as shown in Fig. 3 . 


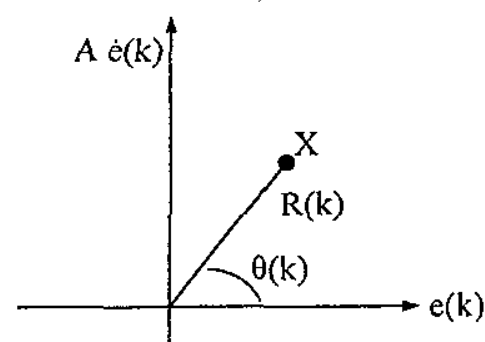

Fig. 3 Phase Plane

The polar displacement $R(k)$ of this point from the origin, and the corresponding angle $\theta(\mathrm{k})$ are computed as:

$$
\begin{aligned}
& R(k)=\left[\left(e_{w}(k)\right)^{2}+\left(A * \dot{e}_{w}(k)\right)^{2}\right]^{0.5} \\
& \theta(k)=\tan ^{-1}\left[\frac{A * \dot{e}_{w}(k)}{e_{w}(k)}\right] \\
& \dot{e}_{w}(k)=\left[\frac{e_{w}(k)-e_{w}(k-1)}{T_{s}}\right]
\end{aligned}
$$

where $T_{s}$ is the sampling interval. In the phase plane the points in the upper half represent the positive acceleration, correspondingly, the points in the lower ha: : represent the negative acceleration, i.e. the deceleration. In addition, the points in the right half plane represent speeds slower than the desired speed, and the points in the left half plane represent speeds faster than the desired one. The origin 0,0 is the desired equilibrium point, and the control efforts should be directed to shift the motor state $\therefore(\mathrm{k})$ towards the origin as soon as possible,

Positive control signal is required when the state $X(k)$ locates in the first quadrant. Negative control signal is required when $X(k)$ locates in the third quadrant. Positive and negative control signals as well are required in the other two quadrants. Two fuzzy membership functions, $N(\theta)$, associated with the desired deceleration and $P(\theta)$ associated with the desired acceleration, are defined in terms of the polar angle $\theta(\mathrm{k})$ to reflect the actions of the control rules. The defining relations for $N(\theta)$ and $P(\theta)$ are:

$$
\begin{aligned}
& N(\theta)=\left\{\begin{array}{cc}
1 & 0 \leq \theta \triangleleft 90 \\
(180-\theta) / 90 & 90 \leq \theta \triangleleft 180 \\
0 & 180 \leq \theta \triangleleft 270 \\
(\theta-270) / 90 & 270 \leq \theta \triangleleft 360
\end{array}\right. \\
& P(\theta)=1-N(\theta) \text { for all } \theta
\end{aligned}
$$

The change of the controller output signal $\Delta \mathrm{U}(\mathrm{k})$ is calculated by:

$$
\Delta U(k)=G(k)[N(\theta)-P(\theta)] U_{\max }
$$

where $\mathrm{G}(\mathrm{k})$ is a gain defined as:

$$
G(k)=\left\{\begin{array}{cc}
R(k) / D r & \text { for } R(k) \triangleleft D r \\
1 & \text { for } R(k) \geq D r
\end{array}\right.
$$

The parameter $\mathrm{Dr}$ is a set value of $R(k)$ at which the gain is fixed at unity and Umax is the maximum value of the control signal which is a prespecified constant parameter.

\section{5- CONTROLLER PARAMETER SELECTION USING GA}

In the proposed fuzzy logic control scheme, the two adjustable parameters are $\mathrm{A}$ and $\mathrm{Dr}$. An iterative approach is used to determine the fuzzy logic controller parameters. To save time at this stage of the design process, a modified version of $\mathrm{GA}$ is utilized to optimally select these parameters. Therefore, the following quadratic performance index, $\mathrm{J}$, is defined by:

$$
J=\sum_{k=1}^{M}\left[\begin{array}{ll}
t_{k} & e(k)
\end{array}\right]^{2}
$$

In the above performance equation, the speed error is weighted by the respective time $t_{k}=K T_{s}$ and, $M$ indicates the total data number. The tuning parameters are coded in a binary string. GA is then used to search for optimal set of parameters that minimizes the performance index. Tournament selection method is used. So, the GA works directly on the given performance index without the explicit definition of a fitness function. The population size is chosen to be 65 strings. The crossover probability is set at 0.75 and the mutation probability at 0.001 .

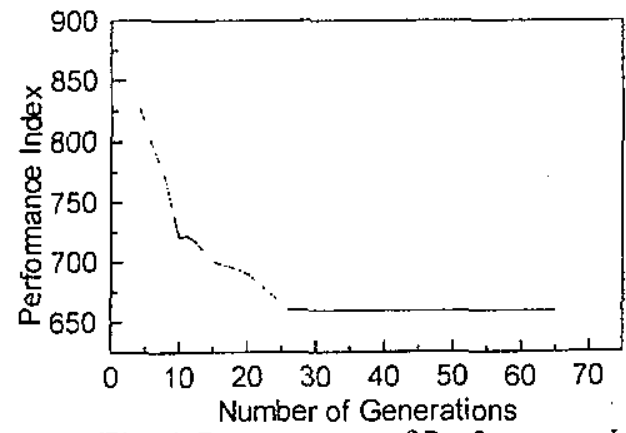

Fig. 4 Convergence of Performance Index

\section{6- EXPERIMENTAL AND SIMULATION RESULTS}

Based on the system model in different modes of operation described in this paper and the parameters given in appendix, a computer program is written to simulate the system. The tuning parameters are precalculated by making step change in reference speed from $500 \mathrm{rpm}$ to $650 \mathrm{rpm}$ and the performance index is calculated during a time interval equal $0.5 \mathrm{sec}$. The GA produced optimal tuning parameters (A, Dr ) equal to 190.0 and 9.5 , respectively. The variation of the performance index $J$ with the number of generation is shown in Fig.4. Also, an experimental circuit has been built to verify the theory and simulation described above. The controller is built by using a DSP1104 digital signal processing board and hence the MOSFET driver pulses are generated. 
Fahmy M. El-Khouly, "A Simple Fuzzy Logic Speed Controller for a DC Motor Fed by SEPIC Converter"
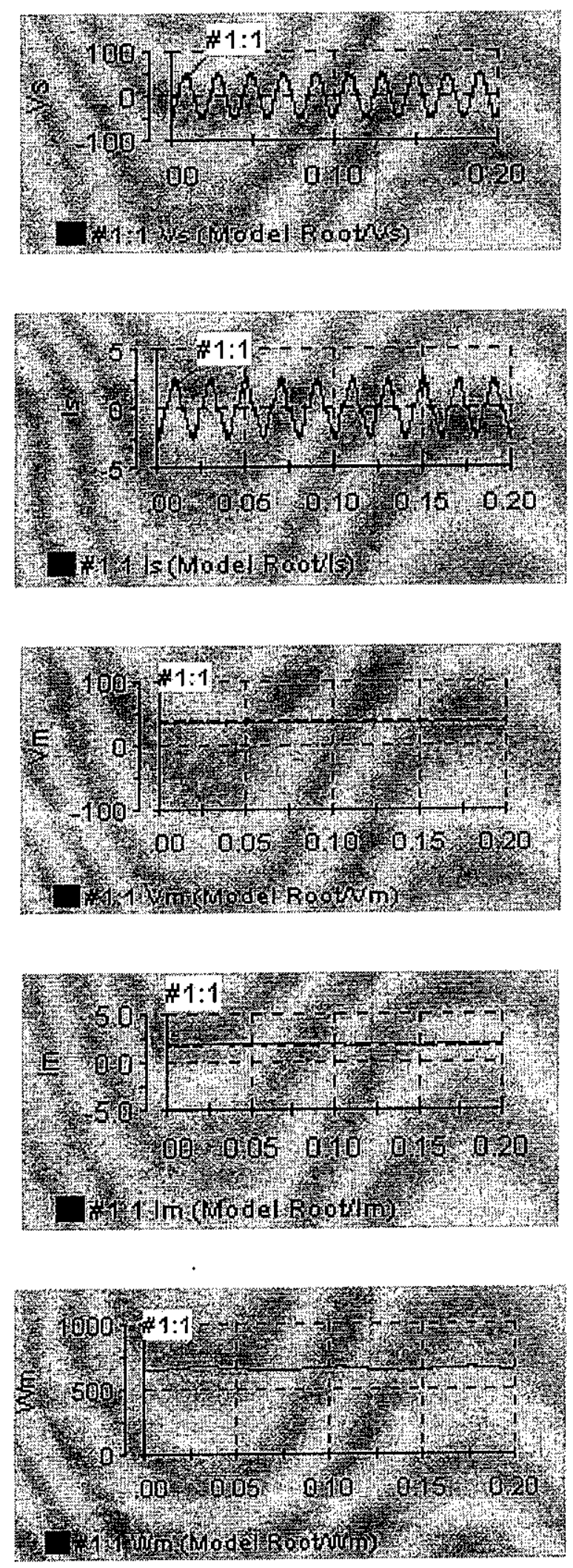

Fig.5 Experimental steady state performance at (Vs) $\max =50(\mathrm{~V})$

and Duty cycle $=0.5$
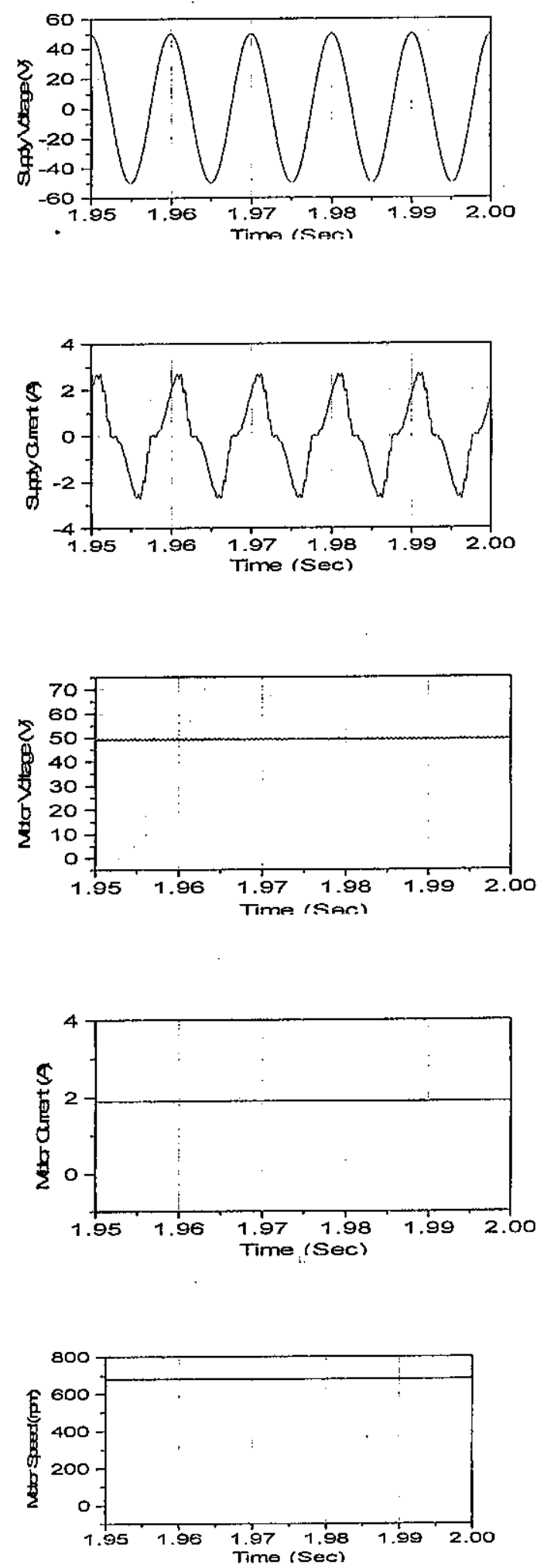

Fig.6 Simulation steady state performance at (Vs) $\max =50(\mathrm{~V})$ and Duty cycle $=0.5$ 
The steady state experimental results of the system with peak value of supply voltage equals 50 volts and a duty ratio 0.5 are shown in Fig.5. It can be shown from the figure that the supply current is sinusoidal with near-unity power factor and both the motor voltage and current are pure dc values. The corresponding simulated results are shown in Fig. 6, which were obtained by simulating the previously mentioned differential equations in different modes of operation. A good agreement between both simulation and experimental results is obtained.

A step change in reference speed, from $500 \mathrm{rpm}$ to $650 \mathrm{rpm}$, under the proposed closed loop speed controller is experimentally shown in Fig.7. Figure 8 indicates the corresponding simulated results. The results indicate the effectiveness of the proposed controller and a good speed response is obtained. Also, the performances of the SEPIC circuit currents and voltages are obtained.

The experimental and simulated system dynamic responses under step changes in motor load are shown in Figs. 9 and 10, respectively. The speed is still following the reference speed with minimum dip at the instants of load changes.

To verify the effectiveness of the proposed controller, Fig. 11 indicates the simulated performance under a wide range of reference speed step changes. The motor speed follows the reference speed with a good performance irrespective of the operating point and the value of the motor load. Also, the performances of the motor terminal voltage and motor current are indicated in Fig. 11. The figure indicates that step-up and step-down characteristics of the motor terminal voltage have been achieved.
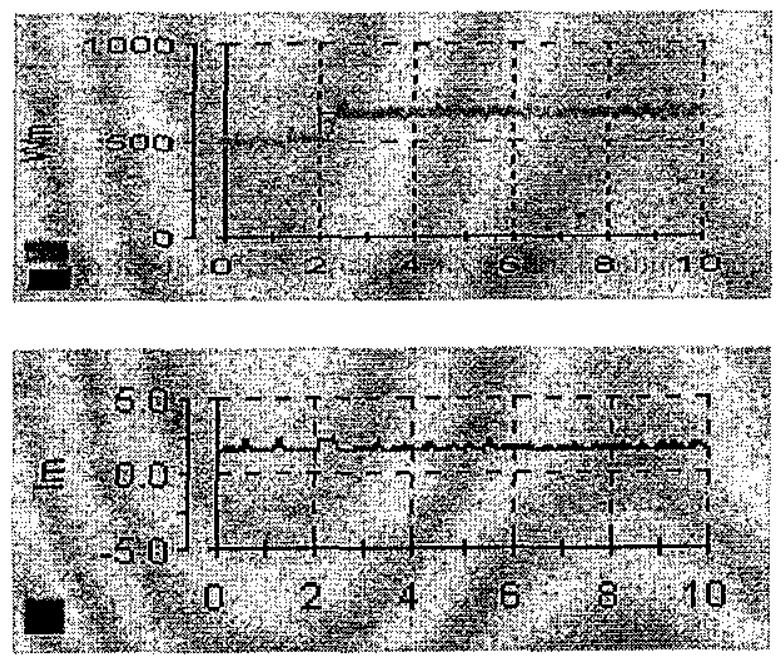

Fig. 7 Experimental Performances under step change in reference speed

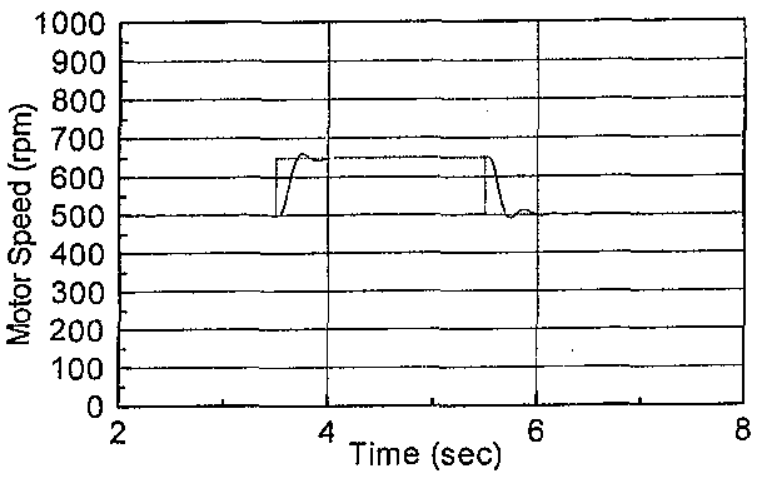

(8-a)

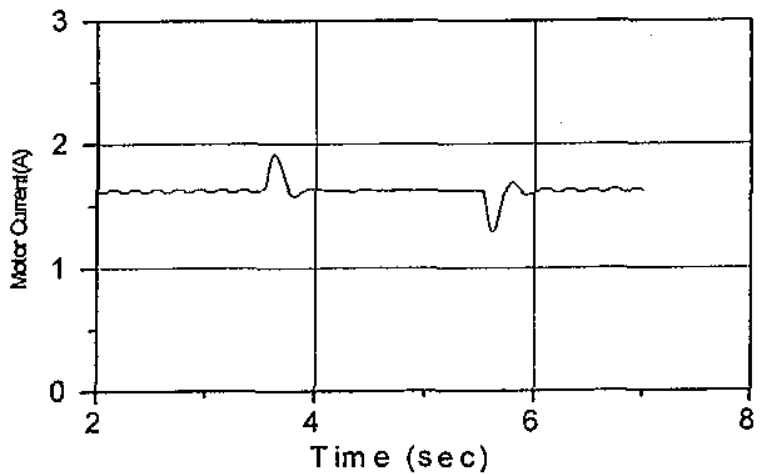

(8-b)

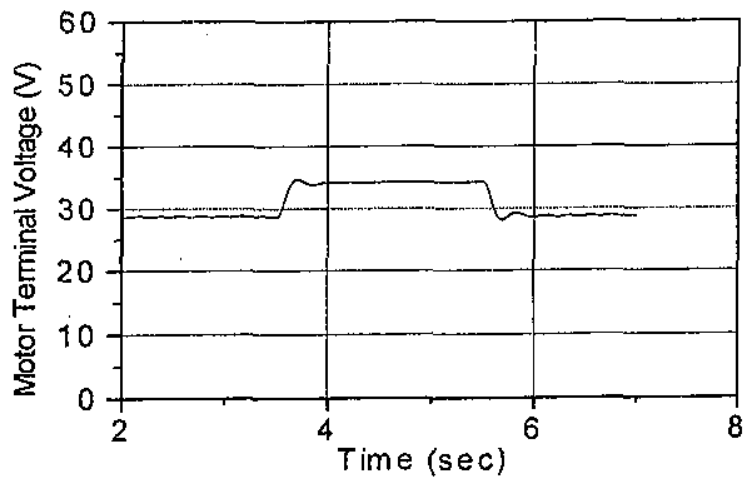

(8-c)

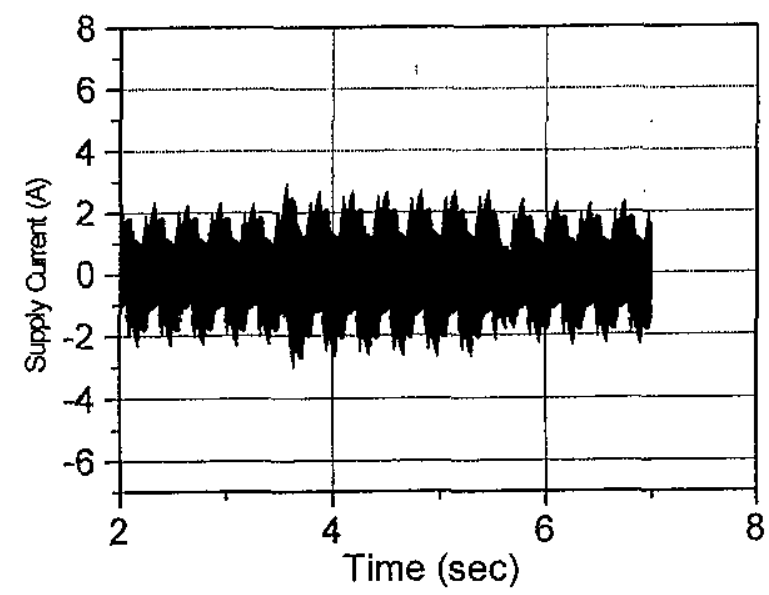

(8-d) 
Fahmy M. El-Khouly, "A Simple Fuzzy Logic Speed COontroller for a DC Motor Fed by SEPIC Converter"

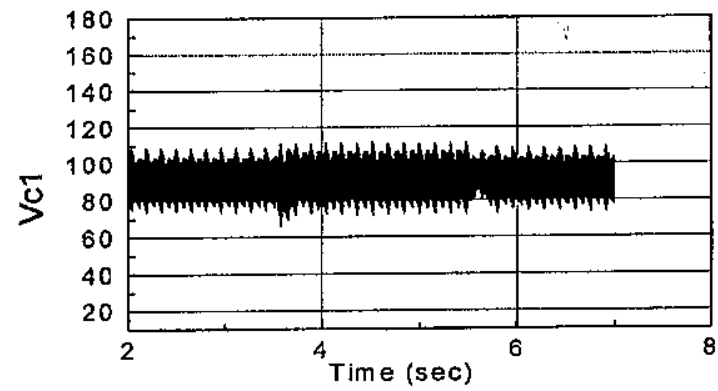

$(8-\mathrm{e})$

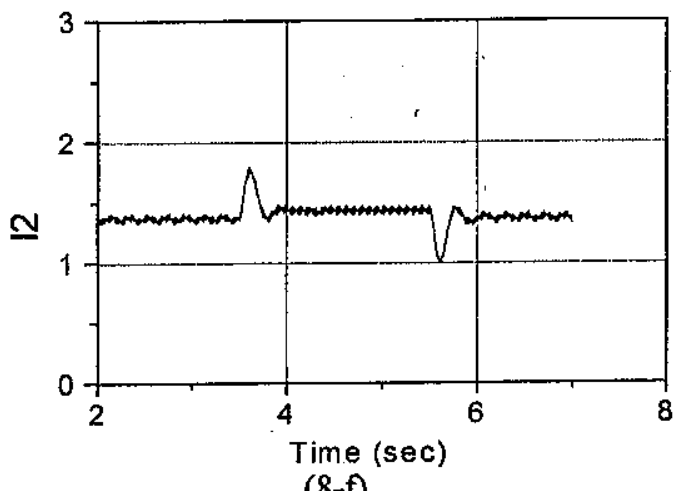

$(8-f)$

Fig. 8 Simulation Performances under step change in reference speed
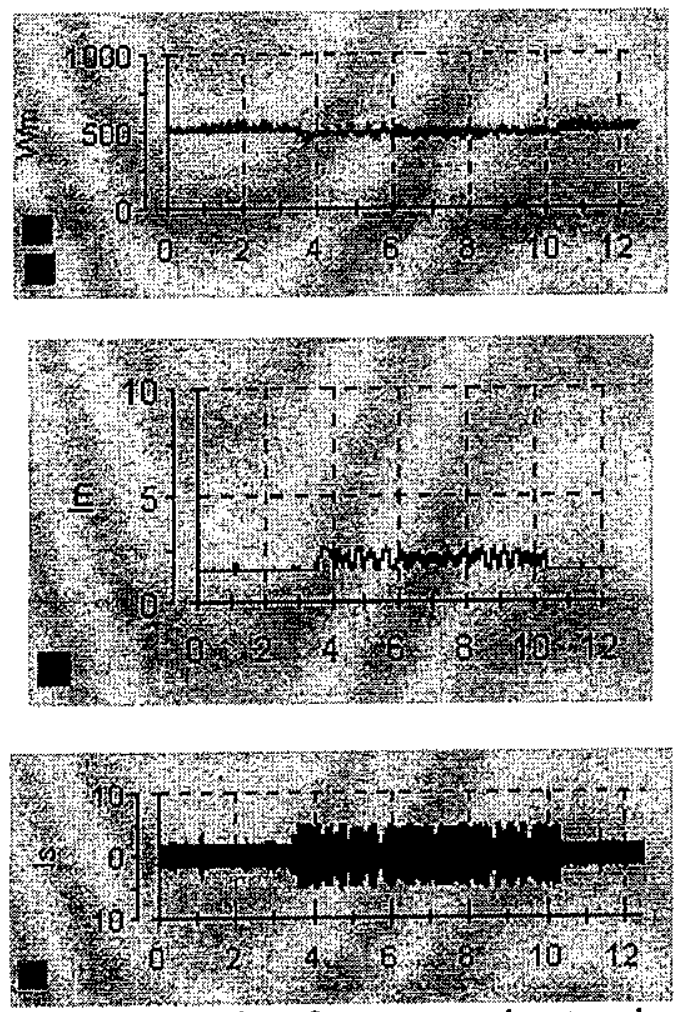

Fig. 9 Experimental Performances under step change in load torque.

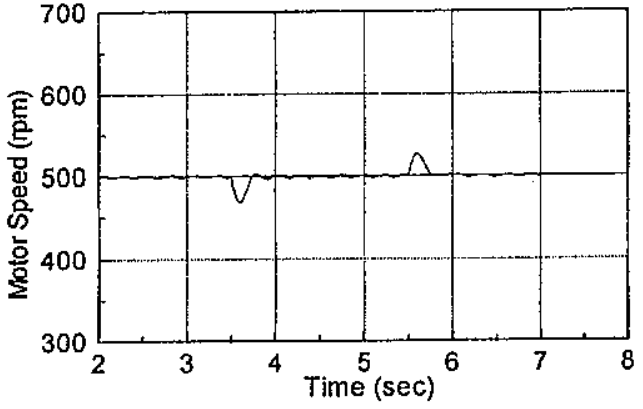

$(10-a)$

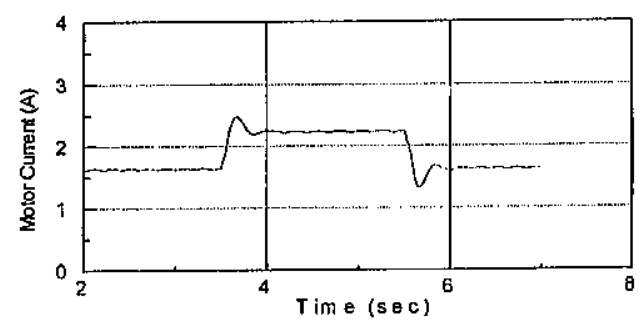

$(10-b)$

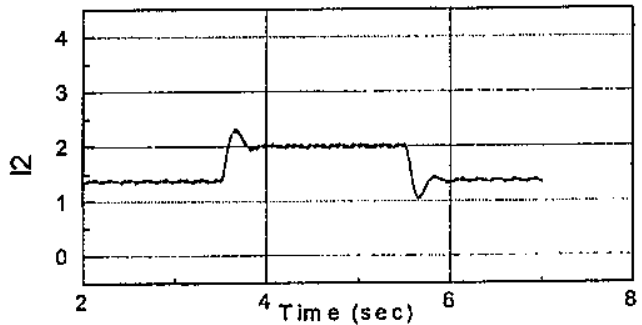

$(10-c)$

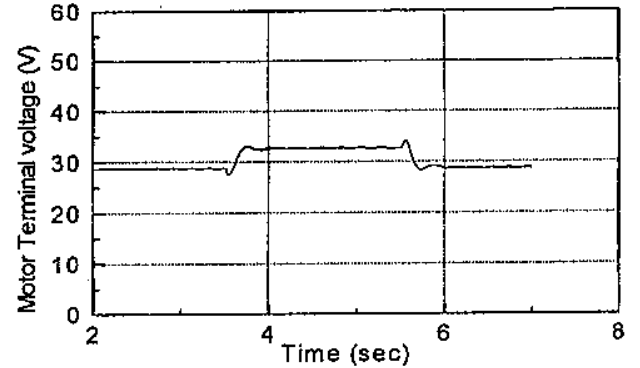

$(10-d)$

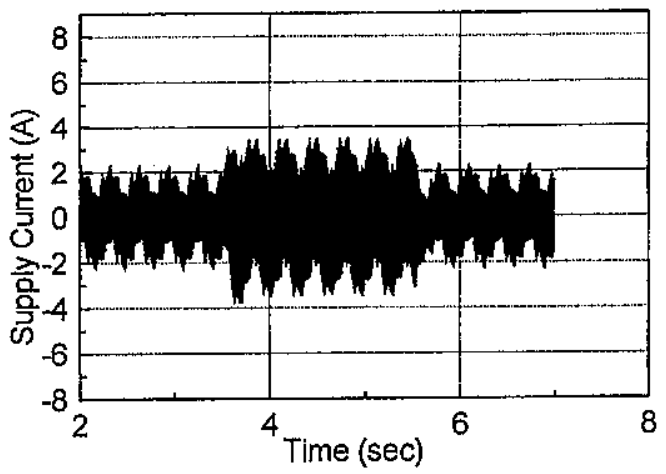

$(10-\mathrm{e})$ 


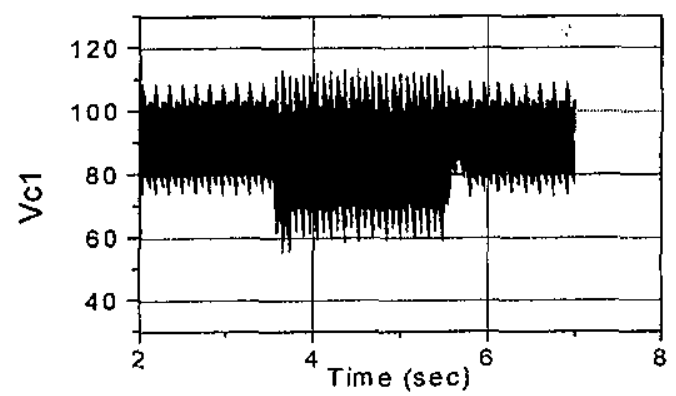

(10-f)

Fig. 10 Simulation Performances under step change in load torque.
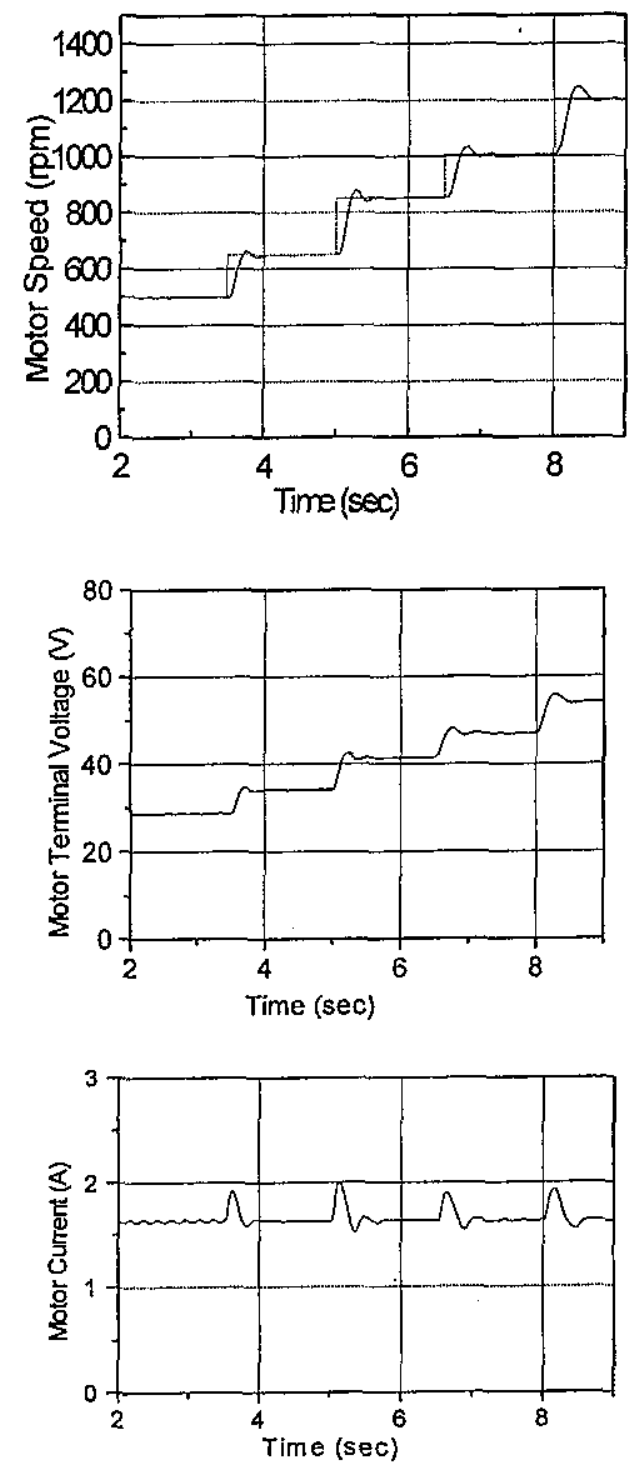

Fig. 11 Simulation Performances under a wide range of step change in reference speed

\section{7- CONCLUSION}

The paper has presented a simple FLC to control the speed of a DC motor fed by SEPIC converter. The FLC has only two membership functions and a GA is used to adaptively tune the controller parameters. The exact system parameters are not required in the implementation of the proposed controller. The controller is easy to implement using microcontroller. The results showed that the performance of the motor drive system is robust, stable, and insensitive to both motor parameters and operating point changes.

The use of SEPIC converter offers an approximately sinusoidal supply current with near unity power factor. Furthermore, step-up and step-down characteristics of the motor input voltage have been achieved

\section{8-REFERENCES}

[1] Y.Y. Hsu and W.C. Chan, "Optimal Variable Structure Controller for DC Motor Speed Control", IEE Proc., Vol. 131, No. 6, November 1984, pp. 233-237.

[2] J. Zhang and T.H. Barton, " Robustness Enhancement of DC Drives With a Smooth Optimal Sliding Mode Control", IEEE Trans. On Ind. Appl., Vol. 27, No. 4, July/August 1991, pp. 686-693.

[3] B.A. White, R.T. lipczynski and A.R. Daniels, " A Simple Digital Control Scheme for DC Motor", IEE Proc. B, Electr. Power Appl. 130, (2), 1983, pp. 143-147.

[4] B. Puthal, "Novel Closed Loop Control Scheme for Thyristor-fed DC Motor", J. Inst. Eng. ( India) Elec. Eng. Drives, 1978, 58, pp. 333-338.

[5] F.M. El-khouly, A.M. Sharaf, A.S. AbdelGhaffar, and A.A. Mohamed" A Rule Based Fuzzy Logic Speed Tracking for Permanent Magnet Chopper Fed DC Motor Drives" Canadian Conference on Electrical and Computer Engineering, September 14-17, 1993, Vancouver, Canada, pp. 1061-1064.

[6] F.M. El-khouly, A.M. Sharaf, A.S. AbdelGhaffar, and A.A. Mohamed" An Adaptive Neural Network Speed Controller for Permanent Magnet DC Motor Drives" 26th IEEE Southeastern Symposium on System Theory, March 20-22, 1994, Athens, Ohio, USA, pp. 416420.

[7] H. Oishi, H. Okada, K. Ishizaka, and R. Itoh, “ SEPIC -Derived Three- Phase Sinusoidal Rectifier Operating in Discontinuous Current Conduction Mode", IEE Oroc. Power Appl. Vol. 142, No. 4, July, 1995, pp.239-245. 
[8] D. S. L. Simonetti, J. Sbastian, and J. Uceda, " The Discontinuous Conduction Mode Sepic and Cuk Power Factor Preregulators: Analysis and Design", IEEE Trans. On Ind. Elec. Vol. 44, No. 5, October, 1997, pp. 630-637.

[9] D.E. Goldberg, "Genetic Algorithms in Search, Optimization, and Machine Learning", Addison" Wealey Publishing Co. USA, 1989.

[10] R.A. Saleh, and H.R. Bolton, "Genetic Algorithm-Aided Design of a Fuzzy Logic Stabilizer for a Super-Conducting Generator",
IEEE Trans. On Power System, Vol. 5, No. 4, 2000, pp. 1329-1335.

\section{APPENDIX}

The DC motor parameters are:

$\mathrm{Ra}=10.5 \Omega, \quad \mathrm{La}=117.83 \mathrm{mH}$,

$\mathrm{Ke}=0.345 \mathrm{~V} / \mathrm{red} / \mathrm{sec}$

And the used SEPIC converter parameters are:

$\mathrm{R} 1=1.5 \Omega, \quad \mathrm{L} 1=0.025 \mathrm{H}$,

$\mathrm{R} 2=1.5 \Omega, \quad \mathrm{L} 2=0.25 \mathrm{H}$,

$\mathrm{C} 1=29 \mu \mathrm{F}, \quad \mathrm{C} 2=1200 \mu \mathrm{F}$ 